\title{
LA MIRADA ECOLÓGICA DEL DESARROLLO HUMANO: HECHOS Y VALORES EN CARITAS IN VERITATE
}

\author{
Richard Orozco C. *
}

\begin{abstract}
RESUMEN
Este artículo presenta una lectura de Caritas in Veritate siguiendo lo que el autor llama racionalidad ecológica, es decir, una perspectiva holista del desarrollo humano. Esa perspectiva ha permitido a Benedicto XVI superar una dicotomía básica de la filosofía cientificista y economicista, a saber, la dicotomía hecho-valor. En la encíclica, Benedicto XVI plantea su crítica al concepto de desarrollo que el mundo contemporáneo pretende, pues reconoce que esta se sostiene sobre la diferenciación de los planos humanos. El resultado: la crisis moral en un mundo que logra avances significativos en ciencia y en economía, contradicciones que hacen evidente la errada mirada dicotómica.
\end{abstract}

PALABRAS CLAVES:

Caritas in Veritate, Benedicto XVI, hecho-valor, ética y economía, subjetivismo moral, ecología, racionalidad ecológica.

\section{THE ECOLOGICAL OUTLOOK OF HUMAN DEVELOPMENT: FACTS AND VALUES CONTAINED IN "CARITAS IN VERITATE"}

\begin{abstract}
This article is an approach - from what the author understands as ecological rationale - to the encyclical letter "Caritas in Veritate", understanding the ecological rationale as the holistic approach of human development. Such perspective has allowed Pope Benedict XVI to over come one basic dichotomy of the scientific and economic philosophy, namely, the fact-value dichotomy. In his encyclical letter, the Pope criticizes the concept of development that the contemporary world seeks to impose, thus acknowledging that it finds its grounds on making a differentiation of human levels. The result is a moral crisis creeping into a world that achieves significant advances in science and economy, contradictions that clearly evidences the erroneous understanding of the dichotomy.
\end{abstract}

\section{KEY WORDS:}

Caritas in Veritate, Benedict XVI, fact-value, ethics and economics, moral subjectivism, ecology, ecological rationale.

\footnotetext{
* Licenciado y Magister por la PUCP. Ganador de la Beca Huiracocha PUCP 2010. Investiga sobre racionalidad científica en la tradición pragmatista. Es co-autor de Pensamiento y Acción. La filosofía peruana a comienzos del siglo XX (PUCP, 2009) y Reflexiones sobre la complejidad educativa (UIGV, 2008). Profesor de la Maestría de Desarrollo Ambiental PUCP y enseña el curso de Filosofía de la Educación en las Maestrías de Educación en la UNIFE, USIL, CHAMPAGNAT.
} 
V oy a presentarles una lectura de la encíclica Caritas in Veritate enfatizando básicamente dos aspectos que, desde mi experiencia en la filosofía, me han parecido sumamente iluminadores. Los dos aspectos a los que me refiero son: uno en la ética y el otro en la ecología. El primero de ellos se resume así: la encíclica muestra una nueva perspectiva ética y axiológica que exige la superación de la dicotomía hecho-valor; y en este sentido, me parece revolucionaria y actual. En un segundo comentario resaltaré más bien el punto de vista ecológico que presenta la encíclica explicando dos formas de entender esa mirada ecológica. Resaltaré también allí, la crítica que el Sumo Pontífice dirige hacia las posiciones ambientalistas más de moda en el ámbito social y empresarial. Comienzo, pues, con mi primer comentario.

\section{LA SUPERACIÓN DE LA DICOTO- MÍA HECHO-VALOR}

Esta nueva perspectiva axiológica se nota ya desde el título mismo de la encíclica. El amor (caritas) es un valor, un sentimiento que popularmente es reconocido en el ámbito de lo subjetivo, en el ámbito de la voluntad. La verdad, en cambio, hace referencia a 'las cosas tal como son'; es decir, al mundo de los objetos físicos, a la naturaleza. Una afirmación sobre dicho mundo - el de los lapiceros, mesas, sillas - es una afirmación que llamamos 'enunciado de hecho'. Por ejemplo, afirmar que 'el lapicero está sobre la mesa' es un 'enunciado de hecho' cuya característica principal es que puede ser definido como verdadero o falso bajo criterios netamente objetivos. En cambio, afirmaciones como 'el amor es valioso', 'la solidaridad es preferible' o 'la fidelidad es necesaria' son más bien 'enunciados de valor' o 'juicios valorativos'. La característica más determinante de esta clase de juicios es que ellos no pueden identificarse como verdaderos o falsos, pues no se remiten a ningún hecho de la naturaleza.

Si afirmo que 'la solidaridad es mejor que el odio' nadie replica diciendo que es verdadera o falsa tal afirmación. Pueden decir que están de acuerdo o en desacuerdo, que coinciden o no, que comparten o no mi creencia; pero nadie se atreve a utilizar el adjetivo 'verdadero' o el adjetivo 'falso' para determinar mi juicio de valor, como nadie se propone diferenciar un gusto verdadero o un placer verdadero o una fe verdadera. No lo hacen, creo yo, debido a dos razones principalmente.

Primero, porque en nuestros tiempos reina sobradamente un subjetivismo axiológico. Según este: todo juicio de valor se refiere exclusivamente al parecer del sujeto y a nada más. Entonces no habría criterios objetivos para definir cuándo algo es valioso o cuando no. Por eso mismo, nadie se atreve a sostener la verdad de un valor porque eso significaría afirmar que hay modelos correctos e incorrectos de lo que es valioso o de nuestras valoraciones. Esto es lo mismo que decir que mis gustos musicales pudieran ser definidos como correctos o incorrectos. Para mucha gente esto significa una intromisión en ámbitos que, creen ellos, les compete de forma exclusiva. En el Medioevo, un dicho muy popular ha sido "de gustibus non disputandum", y hoy, alimentada desde distintas perspectivas, el panorama ético moderno parece conformarse con dicho adagio. Quizá el liberalismo reinante, el individualismo que sustenta a las sociedades capitalistas o las románticas ideas de la autonomía que el cine y la literatura contemporánea promueven han logrado popularizar la creencia en nuestro derecho autojustificado en ser como quiero ser. Charles Taylor ha llamado la atención sobre ese tipo de ética mostrando que le subyacen dos características específicas: una libertad autojustificada y una sub- 
jetivismo axiológico cuyo ideal moral se resume en soy fiel a mi mismo (Taylor, 1994). En la vida diaria esta postura se nota cuando vemos a las personas reclamar por su derecho a ser ellas mismas, y este no es sino su derecho a ser como se quiere ser siempre que no afecten a los demás. La parte más ventajosa de tal perspectiva ética es que no deja espacio a ninguna crítica. Si alguien quiere criticarte o corregirte, tú puedes decir: déjame ser como soy, yo no me meto contigo, tú no te metas conmigo. Taylor ha señalado que esta posición ética es bien comodona, pero innegablemente bastante popular. Y aunque parezca un infantilismo, o una postura ética poco seria; todo lo contrario, tiene un sustento filosófico bastante desarrollado.

Este popular subjetivismo axiológico sería la causa doméstica para diferenciar a los hechos de los valores, pues la idea de fondo es que no hay criterio de corrección en mi ética individual que es lo mismo que decir que el ámbito de la verdad está separado del ámbito de la ética. Pero como dije, hay una razón filosófica, más alturada, para defender tal distinción. Esta razón se remonta al filósofo David Hume, pero ha tenido un desarrollo muy profuso de parte del positivismo decimonónico así como del neo-positivismo lógico del Círculo de Viena. David Hume, reconocido en los manuales de Historia de la Filosofía como un empirista inglés, distinguió dos ámbitos ajenos e inconmensurables: el ámbito del ser y el ámbito del deber-ser. El primero, el ámbito de los hechos, de lo concreto, lo observable, lo verificable; el segundo, el ámbito del valor, de la moral. Para Hume, nada que sea un hecho puede definir el deber-ser, pues estos son planos que ni siquiera se rozan. El ámbito del ser es el de la naturaleza; descriptible y observable. En términos simples sería: las cosas tal como son: la sociedad con su nivel de pobreza, la política con su nivel de corrupción y la naturaleza con sus desastres. Esto sin embargo, es distinto del ámbito ideal, es decir, del ámbito del deber-ser. En este otro ámbito encontramos las cosas como deberían ser: una sociedad donde todos puedan vivir dignamente, unos políticos que verdaderamente trabajen por el bien común y una naturaleza que sea totalmente predecible y controlable. Nótese, pues, que este ámbito del deber-ser es también el ámbito de los deseos. Así lo entendió Hume y así lo han entendido tanto el positivismo como el neo positivismo lógico; y como tal, por ser el ámbito de los deseos, de cómo quisiéramos que fuese el mundo, es completamente distinto de cómo es el mundo y pertenece más bien a la moral. Lo que se quería defender al hacer la distinción es reconocer que una afirmación valorativa (un juicio de valor) solo expresa mis sentimientos, mis emociones (como deberían - quisiera que fuesen las cosas), pero en ningún caso reflejan los hechos de la naturaleza (como las cosas son). De la distinción hecha por Hume, pues, se sostiene lo que llamamos también un emotivismo moral, pues este autor habría reconocido que los juicios morales son lo mismo que expresión de mis deseos. Cuando yo le digo a mi amigo que estuvo mal que haya robado, según Hume, solo habría expresado mi horror y repugnancia por la acción de mi amigo. Hubiese sido lo mismo que si yo hubiese mostrado un gesto de desagrado al decirle con voz de fastidio: irobaste! Es decir, el juicio de valor solo sería una interjección (Hume, 1993).

En el caso de los positivistas, el objetivo era otro. Se trataba más bien de 'limpiar el camino' para reconocer los límites de la ciencia: el único discurso serio que describe cómo son las cosas. Según los positivistas, la ciencia es neutral de las valoraciones pues se encarga solo y exclusivamente de describir hechos. Las valoraciones, pensaban ellos, son expresión de las emociones y los 
sentimientos, en perfecta armonía con el empirismo de Hume, y por ello nada preciso exacto y riguroso se puede decir sobre ellas. Entonces, si lo que queremos es mostrar el ámbito del discurso claro y preciso, exigentemente riguroso, debemos de atenernos a un tipo de discurso que se refiera exclusivamente a los hechos. Debido a ello, los positivistas abogaron por la necesaria diferenciación entre los hechos y los valores, y entre sus respectivos discursos, la ciencia y la moral. En el primero de ellos, en la ciencia, reina la verdad; en cambio, en la moral no puede asumirse la verdad, pues no es un ámbito que pretenda rigurosidad. En la moral a lo más se aproxima a lo útil, pero nunca a la verdad.

Así pues, sea por la razón más doméstica o por la razón más filosófica, los hechos y los valores se han definidos como ámbitos no unibles y de estatutos completamente distintos, y con ello también hemos distinguido la verdad de la moral. Esto, además, tuvo una repercusión en la modernidad que nos enfrenta directamente con el problema del que trata la encíclica. La distinción entre el hecho y el valor llevó a los modernos a desligar radicalmente a la ética de la economía. Más aun, cuando la economía asumió un carácter científico, sus teorías se desligaron aun más de los valores morales y asumieron el modelo tecnocrático con el que hoy muchos las definen. La economía ha encontrado el seguro camino de la ciencia y su pretensión de rigurosidad la ha descubierto impidiendo enturbiarse de cuestiones valorativas o morales. La moral es una cuestión del fuero interno, mientras que la economía se definió como un sistema autónomo, con leyes propias, y ajeno a las cuestiones axiológicas y morales. Dicho sistema es el mercado y su accionar fue definido, ya no a partir de fines y valores, sino desde una mano invisible. Evidentemente, tal situación dicotómica entre la ética y la economía trajo consigo una concepción reducida, chata, del desarrollo a la que Pablo VI se enfrentó con su encíclica Populorum Progressio y ahora Benedicto XVI hace lo propio con su encíclica Caritas in Veritate. Por esa razón, creo yo, le era tan importante para el Papa actual superar la dicotomía hecho-valor, porque así supera una concepción tecnocrática y economicista del desarrollo de los pueblos. Dicho modelo de desarrollo ha demostrado con creces su fracaso; incapaz de responder con ingenio a un mundo desequilibrado por la inequidad, nos ha enfrentado más bien al triste espectáculo de una abundancia de recursos, de la inteligencia artificial, de la comunicación inmediata; pero al mismo tiempo a un mundo de hambre, pobreza y frustración por doquier. El trasfondo, pues, de la superación de dicha dicotomía por parte del Sumo Pontífice en esta encíclica es doble: superar el subjetivismo axiológico, es decir, introducir la verdad en el ámbito de los valores; y al mismo tiempo reconocer que la economía no puede desligarse de la ética si lo que se pretende es lograr el auténtico desarrollo humano que tiene que ver con lo que nosotros como sociedad anhelamos para nuestro futuro y no con la mano invisible de un mercado indolente.

Ante esto, la respuesta del sumo pontífice es clara y directa: ya no se puede sostener las miradas reducidas del desarrollo humano. No basta enfrentar los hechos con fórmulas que pretendan ser moralmente neutras; por el contrario, se trata de reencontrar, para este mundo, valores que realmente movilicen los corazones, gestados con inteligencia y el aporte de nuestros mejores logros científicos. Ciencia y verdad, sí, con fórmulas y técnicas; y sistemas cada vez más rigurosos, metódicamente controlados con la finura de la tecnología cada vez más útil. Pero todo esto no alcanza el auténtico de- 
sarrollo humano, si no está acompañado del amor. Aquí quiero hacer una precisión. Podría pensarse que lo que el Benedicto XVI quiere hacer es mostrar, como San Pablo, que sin el amor la ciencia es solo una campana que resuena. En este caso la acusación que se haría estaría dirigida a la impersonalidad con que trabajan los sistemas científicos y los sistemas económicos. Los ejemplos serían a) la contradicción que supone una comunidad de científicos logrando avances significativos en una disciplina específica, como la neurociencia, al lado de una sociedad que padece, para un alto porcentaje de sus ciudadanos, una escasez de atenciones de salud; y b) el escándalo de una economía nacional que se jacta de resultados azules constantes (o de milagros económicos) pero logrados en una sociedad en la que es significativo el nivel de pobreza y mendicidad. En ambos casos Benedicto XVI habría tenido razón en su crítica, pero esta habría sido nada novedosa y solo habría repetido el discurso catequético que ha tenido ya varias voces desde los años 70 en la que se ha hecho notar especialmente el discurso político de izquierda y, por supuesto, algunos sectores de la iglesia autoproclamados progresistas.

En mi opinión la novedad del mensaje que Caritas in veritate trae, respecto a este tema, radica en que no repite solo la crítica hacia una desarrollo sin amor; sino que profundiza aun más esta tesis de la superación de la dicotomía hecho-valor y llega a reconocer que, en el fondo, aunque el desarrollo tanto científico como económico haya pretendido forjarse neutral a los valores, sin embargo también dicha neutralidad ya es una valor declarado. Quizá no ahonda esta crítica pero es evidente que hacia allí apunta en su novedad metaética: no se trata solo de pretender acercar el desarrollo a los valores cristianos, sino denunciar que el desarrollo que se ha pretendido ya ha estado al servicio de valores camuflados y que en definitiva lo han ideologizado. La actitud profética es aun más radical, pues ya no se trata solo de catequizar el desarrollo hasta ahora concebido, sino de hacer patente su carácter interesado e ideológicamente servil.

Benedicto XVI acusa los extremos opuestos. "Sin verdad, la caridad cae en mero sentimentalismo" (CV.3). Sería el reino del corazón, entusiasta e idealista, pero sin el aporte de la inteligencia, sin las cosas claras, sin criterios ordenadores, sin la precisión y la rigurosidad. La inteligencia permite a los hombres apreciar la verdad de los hechos, las auténticas medidas, nutriendo así de eficiencia sus anhelos de justicia y bienestar. Aquí el Sumo Pontífice habría criticado a ese mundo de 'las buenas intenciones' cuando estas no se acompañan con los aportes de la inteligencia y el desarrollo técnico. Pensar así, solo nos priva de logros mayores, de un auténtico futuro con esperanza.

Por otro lado, la verdad sin la caridad es cientificismo y eso está lejos de ser una auténtica respuesta a un mundo que se vuelve insostenible por la falta de solidaridad y de caridad. Nuevamente Benedicto XVI define el problema con claridad: la crisis mundial es moral, es una crisis de valores. Es una falacia pensar que de la abundancia viene el bienestar. Esa es la falacia del mundo hedonista y consumista en el que vivimos. Pero, aclara el Sumo Pontífice, recordemos que la tan mentada crisis internacional tuvo su origen en los países de mayor abundancia. Así pues, en palabras del Papa: "la economía tiene necesidad de la ética para su correcto funcionamiento" (CV.45)

Lo que está haciendo falta, según la encíclica, más que una inteligencia es una sabiduría. La inteligencia ha sectorizado el saber, lo ha especializado hasta niveles sorprendentes; y ha creado barreras que 
impiden el auténtico diálogo interdisciplinario. Lo más perjudicial ha sido la forma que en la cultura de la actualidad ha cerrado sus oídos a la filosofía y a la teología quienes desde siempre fueron los auténticos forjadores del carácter espiritual de los pueblos. La respuesta al grave problema del mundo en la actualidad no pasa por ese cientificismo tecnocrático; y cito al Papa quien lo dice tan cristalinamente que no haría falta ningún comentarlo: "El saber nunca es solo obra de la inteligencia. Ciertamente, puede reducirse a cálculo y experimentación, pero si quiere ser sabiduría capaz de orientar al hombre a la luz de los primero principios y de su fin último, ha de ser 'sazonado' con la 'sal' de la caridad". Más adelante agrega "no existe la inteligencia y después el amor: existe el amor rico en inteligencia y la inteligencia llena de amor" (CV.30).

\section{EL PUNTO DE VISTA ECOLÓGICO}

El famoso ambientalista anglo-francés Edward Goldsmith ha definido a la ecología como un punto de vista -an ecological world-view- una forma de comprender al mundo (Goldsmith, 1993). Las características con las que Goldsmith define dicho punto de vista son: holístico, teleológico, cualitativo, emocional, crítico, dinámico, integral, etc. Así pues, definir a la ecología como reducida solo al movimiento verde es una mirada chata del valor y el aporte que esta disciplina puede proporcionarnos. La ecología es más bien un método, una forma de encarar integralmente nuestros problemas teóricos y prácticos; sin tanto corte, sin tanta dicotomía, sin tanto sectarismo. La ecología es una racionalidad, una manera de hacer funcionar nuestra razón que intenta responder a los problemas principalmente descubriendo interdependencias, sumando elementos para la comprensión.

Así, la ecología ha revelado que el principal problema de nuestro mundo hoy es su insostenibilidad. Tanto social, como ambientalmente, nuestro mundo no se sostiene. Los desequilibrios han alcanzado niveles alarmantes y ya no se trata solo de una consideración hacia la naturaleza, se trata del futuro del planeta y de las sociedades. Lo que la ecología nos ha mostrado es que el principal equívoco a la hora de enfrentar nuestros problemas, ha sido la mirada selectiva y separatista, la mirada simplificadora que sectoriza los distintos saberes de nuestra cultura. Contra ello la ecología nos ofrece una nueva perspectiva: la mirada holística e integral. Plantear los problemas desde su real complejidad, descubriendo la interrelación de los planos económico, político, social, jurídico, moral.

En mi opinión, Benedicto XVI asume el punto de vista ecológico en la encíclica que estamos comentando; y lo asume en el doble sentido de la palabra. Lo asume como metodología para el análisis del desarrollo humano, es decir, observa a este desde su complejidad interrelacionando planos. Pero también asume el punto de vista ecológico interesándose por los problemas medioambientales; así, en el capítulo IV toma posición sobre los problemas de la sostenibilidad de la naturaleza.

Sobre la primera forma de asumir el punto de vista ecológico vale la pena resaltar que Benedicto XVI se refiere al desarrollo humano integral como una ecología del hombre (CV.51). ¿Cómo entender esta perspectiva? Como encuentro de ámbitos. Ya expliqué en mi primer comentario la forma en que el Sumo Pontífice supera esa dicotomía entre ética y economía. Pero el Papa es consciente que la complejidad de nuestra insostenibilidad es mucha mayor. Así nos dice que "la verdad del desarrollo consiste en su totalidad, si no es de todo el hombre y de todos los hombres no es el verdadero desarrollo" (CV.18). Este princi- 
pio, aparece ya en la Populorum Progressio, es allí donde ya se habla de la necesidad de asumir para el desarrollo la integridad de la persona humana y la totalidad del mundo.

Benedicto XVI remarca que el problema social no depende solo de la economía, sino que es un problema estructural. Así observa que es la falta de una institucionalidad adecuada la que se muestra como escasa para responder a la exigencia de desarrollo. Además, reconoce que el problema pasa por aspectos políticos, pues no se puede seguir desbaratando los derechos laborales a favor de un respaldo hacia las inversiones. Pero para mostrar aún más la integración de los planos a tomar en cuenta, el Papa apunta que la falta de capacidad para enfrentar los peligros que atañen a la sostenibilidad de la vida son también signo de una sociedad que está aceptando la negación y la supresión de la vida. Cito: "la acogida de la vida forja las energías morales y capacita para la ayuda recíproca".

El Papa es más bien cauteloso para referirse a todas estas ideologías extremistas que niegan validez tanto al mercado como al progreso científico. En ambos casos, afirma, no pueden ser asumidos como peligrosos en sí mismos. Las instituciones son siempre dependientes de voluntades, de valores, de fines. Entonces señala más bien la necesidad de no perder de vista la trascendentalidad del ser humano. Evidentemente presenta toda una justificación teológica para esta afirmación que no es tema de mi comentario. Sin embargo, resalto que este aspecto olvidado por las ideologías no integrales del desarrollo, es para Benedicto XVI la causa de sus equívocos y falencias. Tanto así que el Papa toma distancia de la tendencia más actual de la ética empresarial que más bien asumen formas netamente economicistas de la eficiencia, cuando de lo que se trata es de mirar al hombre en su integridad.

\section{REFERENCIAS}

Dewey, J. (2008), Teoría de la valoración. Madrid, Ediciones Siruela.

Goldsmith, E. (1993), The Way. An Ecological World-View. Boston, Shambhala.

Hume, D. (1993), La investigación sobre los principios de la moral. Madrid, Alianza Editorial.

Putnam, H. y Habermas, J. (2008), Normas $y$ valores. Madrid, Trotta.

Putnam, H. (2004), El desplome de la dicotomía hecho-valor y otros ensayos. Barcelona, Paidós.

Taylor, Ch. (1994), La ética de la autenticidad. Barcelona, Paidós. 